\title{
Evaluation and Analysis of Battery Technologies Applied to Grid-Level Energy Storage Systems Based on Rough Set Theory
}

\author{
Zhiyuan $\mathrm{Xie}^{1} \cdot$ Liang $\mathrm{Du}^{1} \cdot$ Xiaojun $\mathrm{Lv}^{1} \cdot$ Qing Wang ${ }^{1} \cdot$ Jianglei Huang ${ }^{1} \cdot$ Tianyi Fu$^{2} \cdot$ Shengyue $\mathrm{Li}^{2}$
}

Received: 10 November 2019 / Revised: 21 November 2019 / Accepted: 10 December 2019 / Published online: 13 February 2020

(c) The Author(s) 2020

\begin{abstract}
Interest in the development of grid-level energy storage systems has increased over the years. As one of the most popular energy storage technologies currently available, batteries offer a number of high-value opportunities due to their rapid responses, flexible installation, and excellent performances. However, because of the complexity, multifunctionality, and wide deployment of power grids, trade-offs in battery performance exist, especially when considering economics, environmental effects, and safety. Therefore, establishing a comprehensive assessment of battery technologies is an urgent undertaking. In this work, we present an analysis of rough sets to evaluate the integration of battery systems (e.g., lead-acid batteries, lithium-ion batteries, nickel/metal-hydrogen batteries, zinc-air batteries, and $\mathrm{Na}-\mathrm{S}$ batteries) into a power grid. Specifically, technological properties, economic significance, environmental effects, and safety of these battery systems are evaluated on the basis of rough set theory. In addition, some perspectives are provided to promote the development of battery technologies for grid-level energy storage.
\end{abstract}

Keywords Grid-level energy storage $\cdot$ Battery $\cdot$ Assessment $\cdot$ Rough set theory

\section{Introduction}

Electrical energy is highly essential in the twenty-first century to promote sustainable economic growth and social prosperity. Ways to generate and utilize electrical power are changing dramatically across the world, thus presenting enormous challenges for power networks to meet transmission and distribution demands with unpredictable daily and seasonal variations. Electrical storage systems, as a technology for storing and supplying electrical energy, could provide a stable, safe, and versatile power source for a large number of applications; thus, these systems play a fundamental role in daily life. In practical use, electrical power storage systems demonstrate multiple attractive functions for power network operations and load balancing, including: (1) storage of surplus power during peak generation periods and provision of vacant power during peak load periods; (2)

Zhiyuan Xie

540625141@qq.com

1 State Grid Zhejiang Zhedian Tendering Consulting Co., Ltd., Hangzhou 310000, Zhejiang, China

2 State Grid Zhejiang Procurement Company, Hangzhou 310000, Zhejiang, China alleviation of the intermittence of renewable energy generation; and (3) assistance in efforts to manage distributed power generation and failure prediction. Considering the expansion and growing complexity of power applications, grid-level electrical energy storage systems are increasingly necessary to address load leveling, alleviate the intermittence of renewable energy supply, regulate frequency, and manage power [1-3].

Batteries are the most desirable electrochemical devices for grid-level electrical energy storage; these devices are characterized by easy modularization and rapid responses [4-6]. Moreover, battery systems demonstrate the important advantages of flexible installation and short construction cycles, thus providing great investment benefits when applied to grid-level energy storage systems $[1,7]$. Recent years, various batteries technologies are successfully developed. The performance of batteries, including their efficiency, cycling life, power, and energy density, has been remarkably improved by emerging technical innovations [8-11]. However, due to the complexity, versatility, and large-scale deployment of electrical storage grids, great challenges are often encountered during the integration of existing battery systems into these grids when taking performance, cost, environmental impacts, and safety issues 
into consideration. As an ideal energy storage system, battery systems should be constructed on the basis of the requirements of grid energy storage applications, which may include high capacity, high energy efficiency, long lifetime, high power and energy densities, and low self-discharge ratio. Moreover, a robust and safe battery module is critical for building an efficient battery system. Assessment of the economic and environmental impacts of batteries in gridscale applications should also be carried out [12]. However, to date, the existing electrochemical battery systems cannot fully meet all requirements because trade-offs often exist in different properties. Therefore, selecting the most appropriate electrochemical battery system to support the development of power grids has attracted wide research interest.

Due to multiple factors influencing the applicability of batteries in power storage systems, the evaluation process for different batteries involves great complexities. Many researchers have focused on assessing the performance of battery units, such as their discharge-charge cycling performance, specific energy, and power density. For example, $\mathrm{Xu}$ et al. [13] presented a semi-empirical lithium-ion batteries (LIB) degradation model that assesses the loss of battery lifetime from operating profiles. Deng et al. [14] developed a cycling life and environmental effect assessment technique for Li-S batteries for electric vehicles. Assunção et al. [15] analyzed the cost, remaining lifetime, and capacity of reused batteries from electric vehicles in their second application as an energy storage system by assessing their technical and economic properties on the basis of the technical performance of different energy storage technologies. Moreover, Fares and Webber [16] assessed the lifetime of batteries in a micro-grid operating in islanded mode by using experimental data. However, although some evaluation methods have been established, most of the proposed indicators focus only on technical aspects. Very few assessments describe the comprehensive assessment of battery storage systems used for power grids. More importantly, a comprehensive and systematic evaluation index system has yet to be formed. Therefore, developing an objective, comprehensive, and quantitative analytical method to assess the operating characteristics (e.g., technological properties, economic significance, environmental impact, and safety) of different energy storage types in the practical use of grid systems is an urgent matter. The complexity of these characteristics introduces many uncertain factors to such an assessment, thus leading to incomprehensive evaluation results. Interestingly, rough set theory, a mathematical tool used to deal with vague and imprecise issues, is considered to be a reasonable, and effective approach to such evaluations $[17,18]$.

In this work, we present the quantitative analytical method of rough sets to evaluate the integration of electrical energy storage systems (e.g., lead-acid batteries [LABs], LIBs, nickel/metal-hydrogen batteries [Ni-MHs], zinc-air batteries [ZABs], and $\mathrm{Na}-\mathrm{S}$ batteries $[\mathrm{Na}-\mathrm{SBs}])$ into a power grid to establish a comprehensive assessment for different battery technologies. Using rough set theory, we assess some key characteristics of battery technologies for energy storage, including their technological properties (e.g., energy efficiency, operating voltage, cycling performance, and energy density), economic significance, environmental impact, and safety, to identify their advantages, and challenges. In addition, perspectives on future directions are presented to provide insights into the development of novel energy storage systems for grid-level energy storage.

\section{Rough Set Theory}

\section{Definition of Rough Set Theory}

Rough set theory, an effective tool used to solve vague and uncertain issues, is a mathematical approach first introduced by Zdzislaw Pawlak, a known mathematician, in the early 1980s [18]. Rough set and fuzzy set theories are similar methods used to treat imprecise data. However, in contrast to the concept of partial membership in fuzzy set theory, rough set theory expresses uncertainty, and imprecision by a boundary region of a set $[19,20]$. The rough set refers to the process of topological operations, also known as approximations [21], and is generally built on the assumption that an information system of the elements of the universe has been established. It comprises a framework that can be used to induce minimal decision rules and further classify objects. Specifically, rough set analysis mainly attempts to direct a reasonable assessment for multiple factors by searching for large databases. The main principles of rough set theory are indiscernibility, approximation, reduction, and decision rules [22]. During rough set analysis, the role of the reduction process is to eliminate redundant attributes, and the obtained reduction set is considered a minimal attributes set, which preserves the partition of the finite objects set and, therefore, serves as the original class [23, 24]. Decision rules are established by combining the reduction attributes set values. Due to the unique advantages of rough set theory in dealing with inaccurate data, research in this area has boomed since the 1990s. Today, rough set theory is recognized as an effective technique for classifying objects [25-27].

Rough set theory is defined as follows $[18,28]$ :

Definition 1 Set $U$ to be a non-empty set and $R$ to be an equivalence relation on $U$. Knowledge information representation system $S$ is defined as follows: $S=(U, R, V, f)$, where $U$, defined as $U=\left\{X_{1}, X_{2}, X_{3}, \ldots, X_{n}\right\}$, is considered the universe of discourse and the set of all samples; $R$, defined as $R=C \cup D$, is the attribute set, in which subset $C$ is a condition attribute set reflecting the feature of objects and $D$ 
represents the decision-making attribute set reflecting the variety of objects; $V$ is an attribute value set defined as $V=\cup_{r \in R} V_{r}$, where $V_{r}$ denotes the range of $r$ values; and $f$ : $U \times R \rightarrow V$ is an information function used to determine the attribute value of every object $x$ in $U$, which means if any $x_{i} \in U, r \in R$, then $f\left(x_{i}, r\right)=V_{r}$.

Definition 2 Set $B$, which is defined as $B \subseteq R$, as the attribute subset. If the object $x_{i}, x_{j} \in U, \forall r \in B$, when if and only if $f\left(x_{i}, r\right)=f\left(x_{j}, r\right)$, then $x_{i}$ and $x_{j}$ are indiscernibility, that can be written as IND $(B)$ in short.

Definition 3 The basic set includes a finite set $(U)$ and the equivalence relation variety of $U(R)$. Then, $K=(U$, $R$ ) denotes the knowledge base. In the knowledge base, if $B \subseteq R$, then $\cap B$ refers to the inter-sets of all equivalence relations in $B$. It is also called the indiscernibility relation of $B$, which can be written as IND $(B)$. Every set of IND $(B)$ is called a basic set.

Definition 4 For an information system $S=(U, R, V, f)$, in which $x$ represents any sample subset $x \subseteq U$ and $R$ has an equivalence relation with $U$, lower and upper approximations are calculated as follows: $R_{-}(X)=\left\{x \in U,[x]_{R} \subseteq X\right\}$; $R^{-}(x)=\left\{x \in U,[x]_{R} \cap X \neq \emptyset\right\}$.

Definition 5 Suppose $r \in R$. If $\operatorname{IND}(R) \neq I N D(R-\{r\})$, then $r$ in $R$ is considered as necessary; otherwise, $r$ is regarded as a redundancy.

Definition 6 In the decision system $S=(U, R, D, V, f)$, assuming that $U / D=\left\{D_{1}, D_{2}, \ldots, D_{k}\right\}$ denotes the division of the domain $U$ by the decision attribute set $D, U / P=\left\{P_{1}, P_{2}\right.$, .., $\left.P_{m}\right\}$ denotes the condition attribute set $P(P \subseteq R)$ for the division of the domain $U$. $\operatorname{pos}_{p}(D)=\frac{U}{D_{i} \in U / D} P\left(D_{i}\right)$ is considered the positive region of $P$ for $D$.

Definition 7 In the information system $S=(U, R, V, f)$, $\forall p \subseteq C$, assuming $U /\{p\}=\left\{P_{1}, P_{2}, \ldots, P_{m}\right\}$, the importance of attribute $p$ is defined as

$\operatorname{sign}(\{p\})=\sum_{i=1}^{m} \frac{\left|P_{i}\right|\left|U-P_{i}\right|}{|U|(|U|-1)}$.

Definition 8 In the information system $S=(U, R, V, f)$, $\forall c_{i} \in R$, and the weight of the attribute $c_{i}$ in the information system is defined as

$\omega\left(\left\{c_{i}\right\}\right)=\frac{\operatorname{sign}\left(\left\{c_{i}\right\}\right)}{\sum_{j=1}^{|c|} \operatorname{sign}\left(\left\{c_{i}\right\}\right)}$.
Processes of Evaluating Batteries Based on Rough Set Theory

The specific steps of the grid application energy storage technology evaluation method based on rough set theory are as follows:

1. Establish the initial information system $S=(U, R, V, f)$. The attribute set of the information system in the comprehensive assessment includes technical properties, cost, environmental effect, and safety issues. The battery technologies to be evaluated are used as the object set in the information system. The data of each attribute obtained from each object are discretized to build an information system $S$.

2. Reduce information system attributes. The information system can be reduced by the discretization method on the basis of rough set theory to calculate uncertain relationships. Reduction of information system attributes refers to the deletion of irrelevant or unimportant attributes while maintaining classification properties. The information system can be simplified through information reduction and removal of unnecessary attributes without losing the basic information of concern. This step can effectively improve the clarity of the information system and help obtain concise decision rules from complex decision systems.

3. Evaluate the calculation of indicator weights. The importance and weight of the attribute (evaluation index) can be calculated based on the reduced information system by using Eq. (1)-(2).

4. Establish a comprehensive evaluation model.

\section{Evaluation of Batteries Based on Rough Set Theory}

\section{Determination of Evaluation Indicators}

Several factors should be considered when choosing and developing a suitable battery technology for a particular application. Evaluating different battery systems to select the most suitable technology is necessary to adapt to complex and multifunctional applications in a grid-level energy storage system. Setting scientific and reasonable evaluation indicators is the first step of comprehensive evaluation. In the present work, a comprehensive and systematic evaluation index system is set up based on technological features, economic significance, environmental impacts, and safety. The characteristics of battery systems that are mainly considered in the assessment process are as follows [16, 29-32]: 
(1) Round-trip efficiency

Round-trip efficiency, also known as the energy efficiency, refers to the ratio of released energy $\left(W_{\mathrm{r}}\right)$ to stored energy $\left(W_{\mathrm{s}}\right)$ and is defined as $\eta=W_{\mathrm{r}} / W_{\mathrm{s}}$; this characteristic represents the amount of stored electricity that can ultimately be extracted from the battery. Good overall efficiency is necessary for a competitive storage system. Good efficiency means the power transfer chain experiences limited loss to realize optimum operations during energy transfer and self-discharge. Therefore, selecting criteria to measure energy conservation goals for daily network load leveling applications is an essential task.

\section{(2) Specific energy}

Specific energy represents the maximum amount of energy accumulated per unit of mass or volume of the battery; this characteristic is especially important for certain applications, in which mass and volume are limited.

\section{(3) Specific capacity}

Specific capacity is defined as the amount of electricity that can be discharged per unit of mass.

\section{(4) Operating voltage}

Operating voltage refers to the voltage of the battery during operation, that is, the potential between the anode and cathode of the battery when the battery is under normal working conditions.

\section{(5) Cycling life}

Cycling life represents the number of times a battery can perform stable discharge-charge cycles and is expressed as the maximum number of cycles $N$; here, one cycle corresponds to the time of one discharge, and one charge means the battery can release the originally designed energy level after each recharge. This characteristic depends on many variables, such as storage technology type and operating conditions.

\section{(6) Self-discharge}

Self-discharge refers to the portion of initially stored energy dissipated over a period of non-use in the form of electrochemical losses in the battery, which is subject to material electrochemistry, battery manufacturing processes, and storage environments.
(7) Cost

Cost is an important economical parameter that affects the total expenditure of energy production. In the present work, the cost is divided by the energy production to obtain the cost per unit of useful energy.

\section{(8) Environmental impact}

Environmental impacts involve all potential pollutions generated during the entire life cycle of battery use. For example, harmful substances discharged into the surrounding environment during a battery's use could pollute water and air during its lifetime. The environmental impact of the residual material after the battery is discarded could also cause pollution; this impact is a dimension that must not be overlooked in the energy storage system.

\section{(9) Safety}

Safety represents the maintenance of good condition and absence of threats to human health under normal use conditions and incident events.

\section{Establishment of an Information System}

Based on the characteristics of various energy storage systems and the requirements of a grid-level energy storage system, we choose five battery systems to analyze promising batteries for application in grid energy storage. These five energy storage technologies (e.g., LABs, LIBs, Ni-MHs, $\mathrm{ZABs}$, and $\mathrm{Na}-\mathrm{SBs}$ ) are taken as examples, recorded as $U=\left\{X_{1}, X_{2}, X_{3}, X_{4}, X_{5}\right\}$, and evaluated using the rough set method. These five battery technologies are used for case analysis based on the above performance index system. The relevant values are shown in Table 1.

\section{Reduction of Information System Attributes}

The performance index of a battery is discretized by using SPSS 16.0 to assess the performance of different battery technologies on the basis of rough set theory. The discretized data results are shown in Table 2.

Since the attribute values of the evaluation objects corresponding to $C_{4}$ and $C_{8}$ are identical, that is, they have the same resolving power, only the attributes of one of these objects need to be retained. Therefore, Table 2 can be further reduced to Table 3 . 
Table 1 Evaluation indices and corresponding parameters of battery technologies [30, 33-37]

\begin{tabular}{|c|c|c|c|c|c|c|c|c|c|}
\hline Battery & $\begin{array}{l}\text { Round-trip } \\
\text { efficiency }(\%)\end{array}$ & $\begin{array}{l}\text { Specific } \\
\text { energy (Wh/ } \\
\mathrm{kg})\end{array}$ & $\begin{array}{l}\text { Specific } \\
\text { capacity (W/ } \\
\text { kg) }\end{array}$ & $\begin{array}{l}\text { Operating } \\
\text { voltage }(\mathrm{V})\end{array}$ & Cycling life & $\begin{array}{l}\text { Self-discharge } \\
\text { ( } \% \text { per day) }\end{array}$ & Cost (\$/kwh) & $\begin{array}{l}\text { Environmen- } \\
\text { tal pollution }\end{array}$ & Safety \\
\hline LABs & 80 & 40 & 180 & 2 & 2000 & 0.2 & 400 & 8 & 5 \\
\hline LIBs & 95 & 250 & 285 & 3.6 & 6000 & 1 & 1000 & 6 & 2 \\
\hline $\mathrm{Ni}-\mathrm{MHs}$ & 70 & 70 & 728 & 1.2 & 2000 & 0.8 & 700 & 4 & 6 \\
\hline ZABs & 60 & 600 & 600 & 1.2 & 400 & 4 & 800 & 2 & 6 \\
\hline $\mathrm{Na}-\mathrm{SBs}$ & 85 & 150 & 160 & 1.8 & 4000 & 20 & 600 & 5 & 2 \\
\hline
\end{tabular}

Table 2 Information system for evaluating battery technologies

\begin{tabular}{llllllllll}
\hline$U$ & $C_{1}$ & $C_{2}$ & $C_{3}$ & $C_{4}$ & $C_{5}$ & $C_{6}$ & $C_{7}$ & $C_{8}$ & $C_{9}$ \\
\hline$X_{1}$ & 2 & 1 & 1 & 2 & 1 & 1 & 1 & 2 & 2 \\
$X_{2}$ & 2 & 2 & 1 & 2 & 2 & 1 & 2 & 2 & 1 \\
$X_{3}$ & 1 & 1 & 2 & 1 & 1 & 1 & 2 & 1 & 2 \\
$X_{4}$ & 1 & 2 & 2 & 1 & 1 & 2 & 2 & 1 & 2 \\
$X_{5}$ & 2 & 2 & 1 & 2 & 2 & 2 & 2 & 2 & 1 \\
\hline
\end{tabular}

Table 3 Reduced information system for evaluating battery technologies

\begin{tabular}{lllllllll}
\hline$U$ & $C_{1}$ & $C_{2}$ & $C_{3}$ & $C_{4}$ & $C_{5}$ & $C_{6}$ & $C_{7}$ & $C_{9}$ \\
\hline$X_{1}$ & 2 & 1 & 1 & 2 & 1 & 1 & 1 & 2 \\
$X_{2}$ & 2 & 2 & 1 & 2 & 2 & 1 & 2 & 1 \\
$X_{3}$ & 1 & 1 & 2 & 1 & 1 & 1 & 2 & 2 \\
$X_{4}$ & 1 & 2 & 2 & 1 & 1 & 2 & 2 & 2 \\
$X_{5}$ & 2 & 2 & 1 & 2 & 2 & 2 & 2 & 1 \\
\hline
\end{tabular}

Table 4 Importance and weight of each performance parameter

\begin{tabular}{llllllllll}
\hline$U$ & $C_{1}$ & $C_{2}$ & $C_{3}$ & $C_{4}$ & $C_{5}$ & $C_{6}$ & $C_{7}$ & $C_{8}$ & $C_{9}$ \\
\hline Importance & 1 & 1 & 1 & 1 & 1 & 0.4 & 1 & 1 & 1 \\
Weight & 0.119 & 0.119 & 0.119 & 0.119 & 0.119 & 0.047 & 0.119 & 0.119 & 0.119 \\
\hline
\end{tabular}

\section{Calculation of Indicator Weights}

According to the definitions described above, the set of all samples $U$ is written as $U=\left\{X_{1}, X_{2}, X_{3}, X_{4}, X_{5}\right\}$, and the attribute set $R$ is defined as $R=\left\{C_{1}, C_{2}, C_{3}, C_{4}, C_{5}, C_{6}, C_{7}\right.$, $\left.C_{9}\right\}$. Then, the importance and weights of the attributes are calculated as follows: $U / \operatorname{IND}(R)=\left\{X_{1}, X_{2}, X_{3}, X_{4}, X_{5}\right\}$, $U / \operatorname{IND}\left(R-C_{1}\right)=\left\{X_{1}, X_{2}, X_{3}, X_{4}, X_{5}\right\} ; U / \operatorname{IND}\left(R-C_{2}\right)=\left\{X_{1}\right.$, $\left.X_{2}, X_{3}, X_{4}, X_{5}\right\} ; U / \operatorname{IND}\left(R-C_{3}\right)=\left\{X_{1}, X_{2}, X_{3}, X_{4}, X_{5}\right\} ; U /$ $\operatorname{IND}\left(R-C_{4}\right)=\left\{X_{1}, X_{2}, X_{3}, X_{4}, X_{5}\right\} ; U / \operatorname{IND}\left(R-C_{5}\right)=\left\{X_{1}\right.$, $\left.X_{2}, X_{3}, X_{4}, X_{5}\right\} ; U / \operatorname{IND}\left(R-C_{6}\right)=\left\{X_{1},\left\{X_{2}, X_{5}\right\}, X_{3}, X_{4}\right\} ; U /$ $\operatorname{IND}\left(R-C_{7}\right)=\left\{X_{1}, X_{2}, X_{3}, X_{4}, X_{5}\right\}, U / \operatorname{IND}\left(R-C_{9}\right)=\left\{X_{1}, X_{2}\right.$, $\left.X_{3}, X_{4}, X_{5}\right\} ; \operatorname{IND}(P)=\operatorname{IND}(Q)=U / \operatorname{IND}(R), \operatorname{pos}_{p}(Q)=\left\{X_{1}\right.$, $\left.X_{2}, X_{3}, X_{4}, X_{5}\right\}, \operatorname{pos}_{R-C_{1}}(Q)=\left\{X_{1}, X_{2}, X_{3}, X_{4}, X_{5}\right\}=5$;
$\operatorname{pos}_{R-C_{2}}(Q)=\left\{X_{1}, X_{2}, X_{3}, X_{4}, X_{5}\right\}=5 ; \operatorname{pos}_{R-C_{3}}(Q)=\left\{X_{1}, X_{2}, X_{3}, X_{4}, X_{5}\right\}=5 ;$ $\operatorname{pos}_{R-C_{4}}(Q)=\left\{X_{1}, X_{2}, X_{3}, X_{4}, X_{5}\right\}=5 ; \operatorname{pos}_{R-C_{5}}(Q)=\left\{X_{1}, X_{2}, X_{3}, X_{4}, X_{5}\right\}=5 ;$ $\operatorname{pos}_{R-C_{6}}(Q)=\left\{X_{1}, X_{2}, X_{3}, X_{4}, X_{5}\right\}=3 ; \operatorname{pos}_{R-C_{7}}(Q)=\left\{X_{1}, X_{2}, X_{3}, X_{4}, X_{5}\right\}=5$; $\operatorname{pos}_{R-C_{9}}(Q)=\left\{X_{1}, X_{2}, X_{3}, X_{4}, X_{5}\right\}=5$

The importance and weights of $C_{1}-C_{9}$ are calculated according to Definitions $7-8$ of rough set theory as shown in Table 4. Technological properties, economic significance, environmental impact, and safety should be of great concern when using battery technologies in energy storage systems, in which self-discharge is not the major limiting factor when selecting and developing the battery system. 


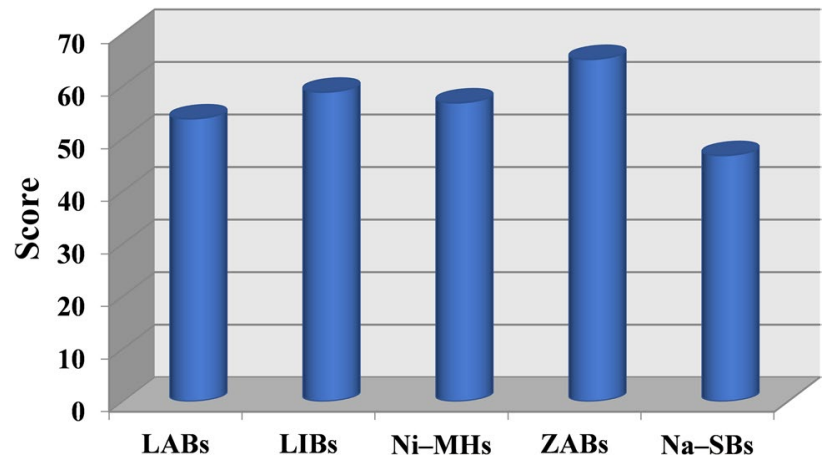

Fig. 1 Evaluation results of the five battery technologies assessed in this work

\section{Comprehensive Evaluation of Battery Technologies}

Assuming the final score of the battery system to be $S, F_{i j}$ represents the score of the $C_{j}$ measure of the $X_{i}$ criterion, and the corresponding weight is $W_{i j}$.

$S=\sum_{i=1}^{5} \sum_{j} F_{i j} \cdot W_{i j}$

The final scores of the five battery technologies determined through pre-research are shown in Fig. 1. Different battery technologies demonstrate unique advantages and disadvantages (Fig. 2). ZABs clearly demonstrate great promise in grid energy storage applications on account of their relatively high specific energy and capacity. Moreover, ZABs are based on zinc electrodes and free-oxygen fuel from the atmosphere and, thus, characterized by low cost, environment friendliness, and safety. Several primary ZABs have been commercialized. However, some challenges to the wide-scale application of ZABs have been noted on account of issues related to their electrodes and electrolytes. For example, air cathodes suffer from sluggish reaction kinetics due to four-electron oxygen reactions, which leads to low discharge voltages, high charge voltages, and low energy efficiency [38, 39]. Besides, in a typical alkaline electrolyte, zinc electrodes interact with the electrolyte, resulting in passivation, and dendrite growth issues, both of which are detrimental to battery life [40]. In addition, owing to the unique half-open structure of ZABs, electrolytes may suffer from issues, such as carbonation in the atmosphere and water loss, during discharge-charge cycling [41, 42]. LABs, which exhibit high specific capacity, high energy efficiency, good cycling durability, and low self-discharge, have long been recognized as reliable energy storage systems. However, the lead content of LABs could pollute the environment and threaten human health, thus limiting their long-term applications. LIBs have been successfully commercialized in portable electronics as power sources due to their attractive features, which include remarkably high round-trip efficiency, high operating voltage, and long cycling life. However, the high price of lithium resources and safety issues result in the limited applications of LIBs in stationary energy storage, so the optimal management and recycling of LIBs are required [43]. Ni-MHs demonstrate great promise in power grid applications due to their relatively high energy density, high specific capacity, long cycling life, and environmental friendliness. However, compared with LABs, Ni-MHs exhibit lower energy efficiency and require much higher cost. In addition, when operated at low temperatures, they suffer from significantly decreased performance. Na-SBs, which show a relatively high efficiency, high operating voltage, and long cycling life, have been used in small-scale energy storage applications. However, safety issues brought about by their high-temperature operating conditions impede their further application.
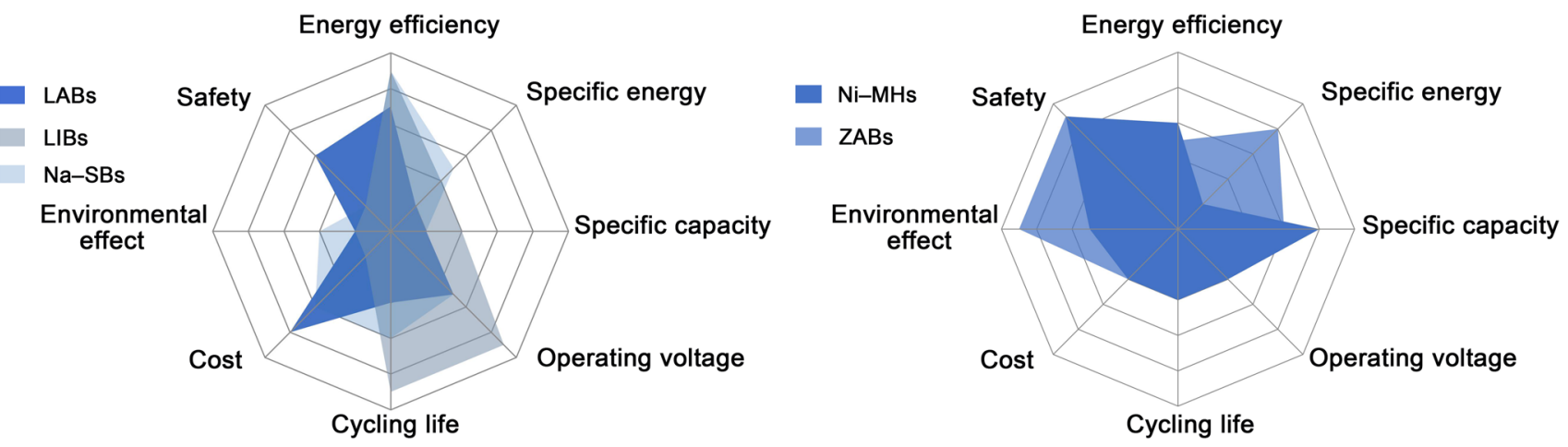

Fig. 2 Radar plots of the five battery technologies assessed in this work 


\section{Conclusions and Outlooks}

Electrical energy grids serving as energy storage and regulatory systems have attracted increasing attention for their ability to address load leveling, alleviate the intermittence of renewable energy supply, and regulate frequency. The success of an electrical energy grid critically depends on progress in the development of efficient power supply systems. Due to their desirable properties, electrochemical batteries are considered promising energy storage devices with many useful applications. In this work, the characteristics of LABs, LIBs, Ni-MHs, ZABs, and Na-SBs are investigated in a grid-level energy storage system. Comprehensive assessment considering key technical properties (e.g., round-trip efficiency, specific energy and capacity, operating voltage, cycling life, self-discharge), economic significance, environmental impacts, and safety issues are conducted on these batteries to establish a perspective on battery technology evaluation. Ultimately, we aim to set up a roadmap to guide future studies and improve grid-level energy storage systems. The most favorable battery technologies in the future will be characterized with high specific energy and capacity, long cycling lifetime, low self-discharge, low cost, environment friendliness, and safety.

Despite considerable progress in battery development, however, many other challenges must be addressed to realize the practical applications of this energy storage system in a grid. Some directions for future work include:

1. Although a large number of battery technologies have been reported, the fabrication of low-cost high-performance batteries with excellent power and energy densities, operating safety, and cycling stability remains a great challenge. In-depth investigations of high-performance and novel battery systems are necessary. Many efforts, for example, to investigate high-performance potassium-ion batteries with relatively high energy density but lower cost compared with LIBs, are ongoing [44].

2. Since standard methods to evaluate battery performance and battery data are lacking, comparison of literature results is difficult. Thus, developing consistent and clear rules to evaluate and compare the performance of different battery technologies is important. For example, the reported current, energy, and power densities of batteries should be calculated based on uniform standards (e.g., test area, mass of consumed active material, and assembled battery volume).

3. Developing high efficiency and low-cost battery manufacturing technologies is highly necessary to meet the large-scale requirements of energy storage grids.
Open Access This article is licensed under a Creative Commons Attribution 4.0 International License, which permits use, sharing, adaptation, distribution and reproduction in any medium or format, as long as you give appropriate credit to the original author(s) and the source, provide a link to the Creative Commons licence, and indicate if changes were made. The images or other third party material in this article are included in the article's Creative Commons licence, unless indicated otherwise in a credit line to the material. If material is not included in the article's Creative Commons licence and your intended use is not permitted by statutory regulation or exceeds the permitted use, you will need to obtain permission directly from the copyright holder. To view a copy of this licence, visit http://creativecommons.org/licenses/by/4.0/.

\section{References}

1. Zhang C, Wei YL, Cao PF et al (2018) Energy storage system: current studies on batteries and power condition system. Renew Sustain Energy Rev 82:3091-3106

2. Wen GH, Hu GQ, Hu JQ et al (2015) Frequency control of sourcegrid-load systems: a compound control strategy. IEEE Trans Ind Inf 12:69-78

3. Lu C, Xu HC, Pan X et al (2014) Optimal sizing and control of battery energy storage system for peak load shaving. Energies 7(12):8396-8410

4. Kong CY, Wu SF, Sun Y et al (2011) Vanadium redox battery system and its energy storage application in wind farm. Adv Mater Res 282-283:112-115

5. Parker CD (2001) Lead-acid battery energy-storage systems for electricity supply networks. J Power Sources 100(1-2):18-28

6. Alotto P, Guarnieri M, Moro F (2014) Redox flow batteries for the storage of renewable energy: a review. Renew Sustain Energy Rev 29:325-335

7. Hameer S, van Niekerk JL (2015) A review of large-scale electrical energy storage. Int J Energy Res 39(9):1179-1195

8. Guo L, Zhang S, Xie J et al (2020) Controlled synthesis of nanosized $\mathrm{Si}$ by magnesiothermic reduction from diatomite as anode material for Li-ion batteries. Int J Min Met Mater 27:1-11

9. Fu J, Liang RL, Liu GH et al (2019) Recent progress in electrically rechargeable zinc-air batteries. Adv Mater 31(31): 1805230

10. Ud Din M, Ramakumar S, Indu MS et al (2019) Advances in electrolytes for high capacity rechargeable lithium-sulphur batteries. Curr Smart Mater 4:1. https://doi.org/10.2174/240546580466619 0617114914

11. Hueso KB, Armand M, Rojo T (2013) High temperature sodium batteries: status, challenges and future trends. Energy Environ Sci 6(3):734-749

12. Dunn B, Kamath H, Tarascon JM (2011) Electrical energy storage for the grid: a battery of choices. Science 334(6058):928-935

13. Xu BL, Oudalov A, Ulbig A et al (2018) Modeling of lithium-ion battery degradation for cell life assessment. IEEE Trans Smart Grid 9(2):1131-1140

14. Deng YL, Li JY, Li TH et al (2017) Life cycle assessment of lithium sulfur battery for electric vehicles. J Power Sour 343:284-295

15. Assunção A, Moura PS, de Almeida AT (2016) Technical and economic assessment of the secondary use of repurposed electric vehicle batteries in the residential sector to support solar energy. Appl Energy 181:120-131 
16. Fares RL, Webber ME (2015) Combining a dynamic battery model with high-resolution smart grid data to assess microgrid islanding lifetime. Appl Energy 137:482-489

17. Pawlak Z (1995) Vagueness and uncertainty: a rough set perspective. Comput Intell 11(2):227-232

18. Rissino S, Lambert-Torres G (2009) Rough set theory-fundamental concepts, principals, data extraction, and applications. In: Ponce J, Karahoca A (eds) Data mining and knowledge discovery in real life applications: I. Tech Education and Publishing, Vienna

19. Pawlak Z (1998) Rough set theory and its applications to data analysis. Cybern Syst 29(7):661-688

20. Yao YY (1998) A comparative study of fuzzy sets and rough sets. Inf Sci 109(1-4):227-242

21. Shidpour H, da Cunha C, Bernard A (2016) Group multi-criteria design concept evaluation using combined rough set theory and fuzzy set theory. Expert Syst Appl 64:633-644

22. Agreira Cif, Ferreira Cmm, Pinto JD et al (2004) Electric power systems steady-state security assessment using the rough set theory. In: 2004 international conference on probabilistic methods applied to power systems. Ames, USA, pp 873-877

23. Li H, Li DY, Zhai YH et al (2016) A novel attribute reduction approach for multi-label data based on rough set theory. Inform Sci 367:827-847

24. Jelonek J, Krawiec K, Slowiński R (1995) Rough set reduction of attributes and their domains for neural networks. Comput Intell 11(2):339-347

25. Hor CL, Crossley PA (2006) Substation event analysis using information from intelligent electronic devices. Int J Electr Power Energy Syst 28(6):374-386

26. Sharma S, Dua A, Singh M et al (2018) Fuzzy rough set based energy management system for self-sustainable smart City. Renew Sustain Energy Rev 82:3633-3644

27. Bai CG, Sarkis J (2010) Green supplier development: analytical evaluation using rough set theory. J Clean Prod 18(12):1200-1210

28. Ji ZG, Zhang PJ, Zhao ZW (2009) Application of wavelet neutral network and rough set theory to forecast mid-long-term electric power load. In: 2009 first international workshop on education technology and computer science, March 7-8, 2009. Wuhan, Hubei, China

29. Barelli L, Bidini G, Bonucci F (2016) A micro-grid operation analysis for cost-effective battery energy storage and RES plants integration. Energy 113:831-844

30. Chen HS, Cong TN, Yang W et al (2009) Progress in electrical energy storage system: a critical review. Prog Nat Sci 19(3):291-312

31. Chacra FA, Bastard P, Fleury G et al (2005) Impact of energy storage costs on economical performance in a distribution substation. IEEE Trans Power Syst 20(2):684-691

32. Fan XY, Liu XR, Hu WB et al (2019) Advances in the development of power supplies for the Internet of Everything. InfoMat 1(2):130-139

33. Alhamali A, Farrag ME, Bevan G et al (2016) Review of energy storage systems in electric grid and their potential in distribution networks. In: 2016 Eighteenth international middle east power systems conference (MEPCON) Cairo, Egypt

34. Mousazadeh H, Keyhani A, Javadi A et al (2010) Evaluation of alternative battery technologies for a solar assist plug-in hybrid electric tractor. Transp Res Part D Transp Environ 15(8):507-512
35. Li YB, Fu J, Zhong C et al (2019) Batteries: Recent advances in flexible zinc-based rechargeable batteries (adv Energy mater 1/2019). Adv Energy Mater 9(1):1970001

36. Luo X, Wang JH, Dooner M et al (2015) Overview of current development in electrical energy storage technologies and the application potential in power system operation. Appl Energy 137:511-536

37. Sun YT, Liu XR, Jiang YM et al (2019) Recent advances and challenges in divalent and multivalent metal electrodes for metal-air batteries. J Mater Chem A 7(31):18183-18208

38. Wang YJ, Fang BZ, Zhang D et al (2018) A review of carboncomposited materials as air-electrode bifunctional electrocatalysts for metal-air batteries. Electrochem Energ Rev 1(1):1-34

39. Liu XR, Yuan YF, Liu J et al (2019) Utilizing solar energy to improve the oxygen evolution reaction kinetics in zinc-air battery. Nat Commun 10:4767

40. Zhao ZQ, Fan XY, Ding J et al (2019) Challenges in zinc electrodes for alkaline zinc-air batteries: obstacles to commercialization. ACS Energy Lett 4(9):2259-2270

41. Fan XY, Liu J, Song ZS et al (2019) Porous nanocomposite gel polymer electrolyte with high ionic conductivity and superior electrolyte retention capability for long-cycle-life flexible zinc-air batteries. Nano Energy 56:454-462

42. Li M, Liu B, Fan XY et al (2019) Long-shelf-life polymer electrolyte based on tetraethylammonium hydroxide for flexible zinc-air batteries. ACS Appl Mater Interfaces 11(32):28909-28917

43. Li L, Zhang XX, Li M et al (2018) The recycling of spent lithiumion batteries: a review of current processes and technologies. Electrochem Energ Rev 1(4):461-482

44. Ding J, Zhang HL, Zhou H et al (2019) Potassium-ion batteries: sulfur-grafted hollow carbon spheres for potassium-ion battery anodes (adv Mater 30/2019). Adv Mater 31(30):1970217

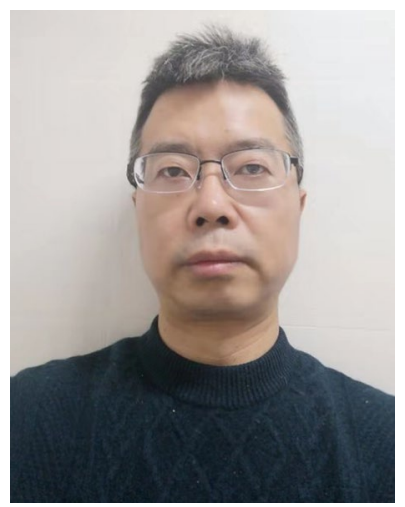

Zhiyuan Xie graduated from Gezhouba Hydropower Engineering College in July 1996. After that, he was engaged in relay protection commissioning in the commissioning company of Zhejiang Transmission and Transformation Engineering Company from August 1996 to June 2004. He worked as a substation engineer and engaged in project management in the project management department of Zhejiang Power Transmission and Transformation Engineering Company from July 2004 to June 2007. From July 2007 to present, he engaged in the bidding practice and management in State Grid Zhedian Tendering and Consulting Co. Ltd. 